\title{
Forward-viewing echoendoscope-guided pancreatic duct drainage using a diathermic dilator for a severely stenotic pancreaticojejunal anastomosis
}

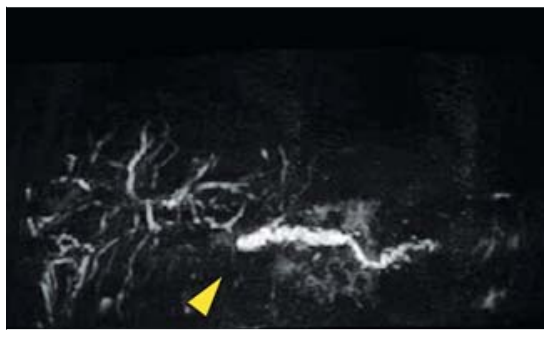

Fig. 1 Magnetic resonance cholangiopancreatography image showing the dilated main pancreatic duct (yellow arrowhead).

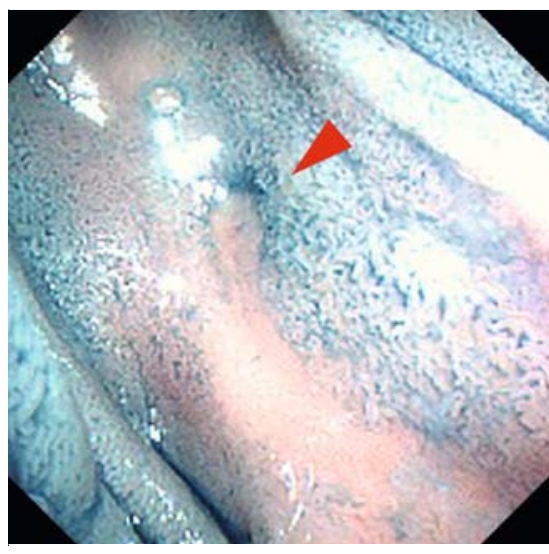

Fig. 2 Conventional endoscopic view using indigo carmine dye showing the pancreaticojejunostomy, with a pinholelike appearance (red arrowhead).

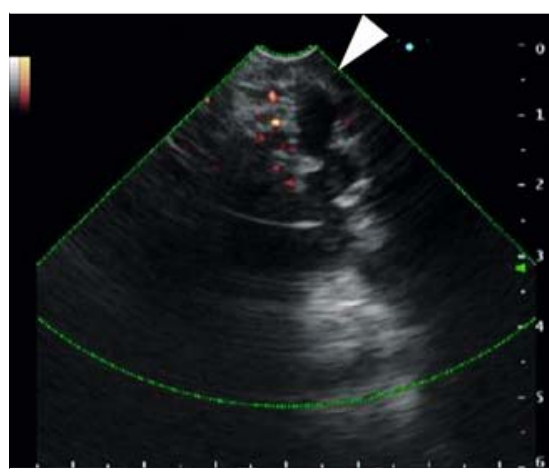

- Fig. 3 Forward-viewing endoscopic ultrasound image showing the dilated main pancreatic duct near the pancreaticojejunostomy (white arrowhead).

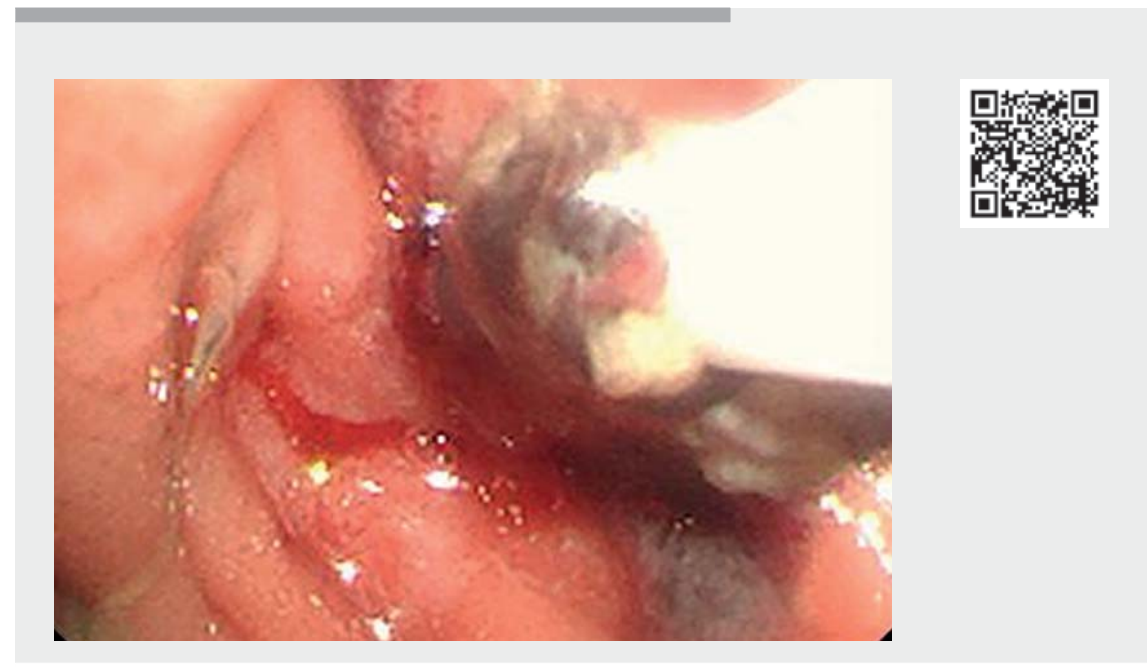

$\checkmark$ Video 1 Forward-viewing echoendoscope-guided pancreatic stent placement using a diathermic dilator for a severely stenotic pancreaticojejunal anastomosis.

Pancreatic duct (PD) drainage is mainly indicated for main pancreatic duct (MPD) stenosis owing to chronic pancreatitis and stenotic surgical anastomoses. Transpapillary or transanastomotic PD drainage can be performed by endoscopic retrograde pancreatography (ERP) or balloon-assisted ERP but, for difficult cases, percutaneous or surgical PD drainage is considered [1-3]. Recently, endoscopic ultrasound (EUS)-guided PD drainage has been reported, with a high success rate [4].

Here, we present the case of a patient with a stenotic pancreaticojejunal anastomosis after pylorus-preserving pancreaticoduodenectomy with the Imanaga reconstruction (PPPD-Imanaga), in which a pancreatic stent was successfully placed using a forward-viewing echoendoscope and diathermic dilator. An 80-year-old man with carcinoma of the papilla of $\mathrm{Va}$ ter who had undergone PPPD-Imanaga presented with abdominal symptoms and an elevated serum amylase level. Magnetic resonance cholangiopancreatography showed a dilated MPD without any recurrent masses, which was sug- gestive of stenosis of the anastomosis (ฉ Fig.1). Repeated attempts during transanastomotic ERP failed to cannulate the MPD, so EUS-guided PD drainage was performed ( $\vee$ Video $\mathbf{1}$ ).

The PPPD-Imanaga is designed to create an end-to-end gastrojejunostomy, followed by an end-to-side pancreaticojejunostomy, and a choledochojejunostomy, meaning it is easy to reach the pancreaticojejunal anastomosis on upper gastrointestinal endoscopy [5]. In this case, EUS with a forward-viewing echoendoscope (TGF-UC260]; Olympus, Tokyo, Japan) confirmed the pancreaticojejunal anastomosis and dilation of the MPD to $6 \mathrm{~mm}$ in diameter ( $>$ Fig. 2 and $>$ Fig. 3 ). The MPD was punctured using a 19-gauge needle, which was confirmed by the injection of contrast medium ( $>$ Fig.4). A guidewire was passed through the MPD and, because of the hard scar tissue around the anastomosis site due to the surgery, the puncture site was dilated using a diathermic dilator (Fine 025; Medico's Hirata Inc., Osaka, Japan). Next, a 7-Fr plastic stent was placed into the MPD ( $>$ Fig.5). The devices were easily inserted because 


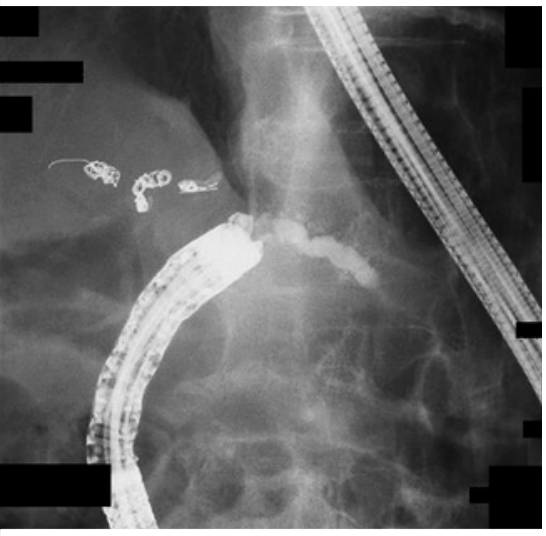

> Fig. 4 Fluoroscopic image showing the dilated main pancreatic duct after the injection of contrast medium, following duct puncture with a 19-gauge needle.

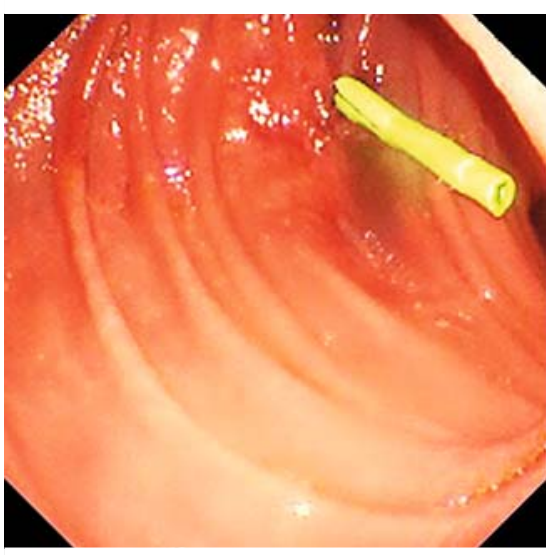

- Fig. 5 Conventional endoscopic view showing the plastic stent placed into the main pancreatic duct through the duodenal mucosa near the pancreaticojejunostomy.

the axis of the forward-viewing echoendoscope and that of the guidewire were the same.

EUS-guided PD drainage using a forwardviewing echoendoscope and a diathermic dilator may prove useful in patients with stenotic anastomoses, especially those that are complicated with postoperative hard scar formation.

Endoscopy_UCTN_Code_TTT_1AS_2AD

\section{Competing interests}

The authors declare that they have no conflict of interest.

The authors

\section{Kenji Nakamura1 ${ }^{\complement}$, Yutaka Takigawa², Yuki}

Masuda², Tadashi Katayama', Hiroshi

Kishikawa ${ }^{1}$, Junichi Matsui ${ }^{2}$, Jiro Nishida ${ }^{1}$

1 Department of Gastroenterology, Tokyo Dental College, Ichikawa General Hospital, Chiba, Japan

2 Department of Surgery, Tokyo Dental College, Ichikawa General Hospital, Chiba, Japan

\section{Corresponding author}

\section{Kenji Nakamura, MD, PhD}

Department of Gastroenterology, Tokyo Dental College, Ichikawa General Hospital, 5-11-13, Sugano, Ichikawa, 272-8513, Chiba, Japan

kenakamura@tdc.ac.jp

\section{References}

[1] Dumonceau JM, Delhaye M, Tringli A et al. Endoscopic treatment of chronic pancreatitis: European Society of Gastrointestinal Endoscopy (ESGE) Guideline - Update August 2018. Endoscopy 2019; 51: 179-193

[2] Chahal P, Baron TH, Topazian MD et al. Endoscopic retrograde cholangiopancreatography in post-Whipple patients. Endoscopy 2006; 38: 1241-1245
[3] Kamo M, Miyazawa R, Nishiyama T et al. Percutaneous transgastric pancreatic duct drainage for pancreaticojejunal leak after pancreaticoduodenectomy. Diagn Interv Radiol 2019; 25: 471-472

[4] Basiliya K, Veldhuijzen G, Gerges C et al. Endoscopic retrograde pancreatographyguided versus endoscopic ultrasound-guided technique for pancreatic duct cannulation in patients with pancreaticojejunostomy stenosis: a systematic literature review. Endoscopy 2021. doi:10.1055/a-12000199

[5] Hashinuma S, Ogata Y, Matsui ] et al. Evaluation of pylorus-preserving pancreatoduodenectomy with the Imanaga reconstruction by hepatobiliary and gastrointestinal dual scintigraphy. Br J Surg 1999; 86: 13061311

\section{Bibliography}

Endoscopy 2022; 54: E75-E76

DOI 10.1055/a-1388-5913

ISSN 0013-726X

published online 15.3.2021

(c) 2021. Thieme. All rights reserved.

Georg Thieme Verlag KG, Rüdigerstraße 14, 70469 Stuttgart, Germany

\section{ENDOSCOPY E-VIDEOS}

https://eref.thieme.de/e-videos

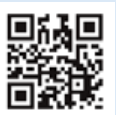

Endoscopy E-Videos is an open access online section, reporting on interesting cases and new techniques in gastroenterological endoscopy. All papers include a high quality video and all contributions are freely accessible online. Processing charges apply (currently EUR 375), discounts and wavers acc. to HINARI are available.

This section has its own submission website at

https://mc.manuscriptcentral.com/e-videos 